\title{
HIGH STAKES: OFFENDER DECISIONS ABOUT WEAPON CARRYING AND WEAPON USE
}

Author: Iain R. Brennan

Affiliation: School of Social Sciences, University of Hull.

Research interests: Iain Brennan is a Senior Lecturer in Criminology and Psychology at University of Hull, UK. His research interests include weapon use, alcohol-related violence and victim responses to crime.

\section{Weapons}

This chapter describes the contradictory roles that weapons play in offender decision-making as mechanisms that can both increase the physical harm to a victim of violence but also reduce the need for physical harm in victims of robbery. As weapons serve simultaneously offensive and defensive purposes, the way in which offenders carry and use weapons is subject to a complex decision-making process. This process is presented and interpreted from a rational perspective, incorporating an offender's calculation of potential benefits and costs as well as the uncertainty of a victim's response. A rational analysis of weapon carrying and use is presented alongside research evidence suggesting that culture and availability are important influences on weapon of choice and weapon-related behaviour. The chapter concludes with a review of the effectiveness of weapons in reducing victim resistance and retaliation showing that weapon use is a high reward-high cost activity. 


\section{WEAPONS}

Weapons are the tools of interpersonal violence, power and control. The potential they have for causing serious injury gives them a contradictory power: they can be used to do serious violence or to reduce the likelihood of any violence; they can deescalate an altercation or prime aggressive behaviour; and they can be essential mechanisms for self-protection while also being offensive and dangerous. These contradictions make weapon carrying and use fascinating but complicated areas to study and this complexity can be seen both in public and academic debate. Throughout the chapter, when thinking about offender decisionmaking, it is important to recall the many overlapping and often contradictory functions that weapons fulfil for users. Binary interpretations of weapons as having purely offensive or defensive functions will limit our ability to understand offender decision-making and should be avoided wherever possible. This chapter is divided into four main sections that relate to the decision to carry and use a weapon: (1) how we define and learn about weapon use in crime; (2) why and how weapons can affect the success of a crime; (3) why offenders choose to carry and use weapons; and finally (4) a discussion of how weapon use actually affects the success of a crime.

\section{HOW WE DEFINE AND LEARN ABOUT WEAPON USE IN CRIME}

\subsection{Definition}

Any attempt to define weapons emphasises the fractious nature of the concept. Dawson and Goodwill (2013) defined a weapon as "an object used to cause or threaten injury to another" (p.20). This is a useful definition that covers most forms of violence with a weapon. However, it fails to specify the intentional nature of violence, overlooks the fact that not all violence results in injury and does not acknowledge the potential use of weapons against oneself. Some minor amendments to their definition can accommodate these issues - "an object deliberately used to do or threaten violence to another". This definition would exclude fire and computer viruses among others, which some would regard as weapons and it would include boots and a rope used in suicide, which many would not regard as weapons. The need to establish a watertight definition of weapon is not the aims of this chapter and the majority of studies detailed below describe weapons in broad categories of firearm, sharp object, blunt object and other weapon type. 
Further difficulties emerge when we seek to define 'weapon carrying' and 'weapon use'. Most of the studies that have explored weapon carrying and use have used binary categories to identify those who have and have not engaged in these behaviours, but this underestimates the many ways in which a person comes to be in possession of or use a weapon. At first instance, it might appear that weapon users must first be weapon carriers, but as can be seen from victimisation surveys (Office for National Statistics, 2013) and offender accounts (Feeney, 1986), a great many violent incidents involved 'environmental' or 'situational' weapons such as beer glasses which were not carried on the user's person before use. For example, in England and Wales, 50\% of intimate partner murders involve a weapon, but these weapons are usually kitchen knives and available blunt objects found at the scene rather than weapons brought to the scene for the purpose of violence (Home Office, 2014). We should remember that the study of weapon use as a behaviour is in its infancy and the crude techniques currently used for categorising these behaviours will be refined over time. Furthermore, just as with other types of crime, scaling weapon-related behaviour is problematic. It is likely that combining the frequency and diversity of weapon-related behaviours will provide the best discrimination between low and high risk offenders (Sweeten, 2012).

\subsection{Measuring and examining the carrying and use of weapons}

Most countries and districts have some legislation that regulates or prohibits the carrying and use of weapons. The illicit and deviant nature of weapon carrying (where it is prohibited) impairs the accurate measurement of this behaviour. Furthermore, the contested and fleeting nature of what constitutes a weapon also impairs the accurate measurement of this behaviour. If a person walking along a dark street at night pushes a set of keys in their pocket between their fingers to form a makeshift knuckleduster, is this a weapon? If so, if a person knows the keys in their pocket could become a weapon at short notice and is reassured by this knowledge, are they a weapon carrier? Limiting the definition of weapon-carrying to knives, firearms and blunt objects may solve category errors, but it underestimates the diverse range of objects that people regard as weapons.

The measurement of weapon use is also difficult. Many offenders will be reluctant to admit to this serious violence. Victimisation surveys and police reports are an alternative source of data on the prevalence of weapon use. However, for a number of reasons, many victims do not report their victimisation, which results in a biased sample of police data or victimisation 
survey data. While victimisation surveys suffer from under-reporting, they are usually more reliable than police records. However, it should be noted that weapon use has been shown to almost double the likelihood of victim reporting of violence (I.R. Brennan, 2011a), suggesting that police data may not be a gross underestimations of weapon use prevalence but may result in an overestimation of the prevalence of weapon use relative to other violence.

With these limitations in mind, the Crime Survey for England and Wales found that, in 2012/13, weapons were used in approximately $20 \%$ of non-fatal violent incidents and over half of homicides (Office for National Statistics, 2014). Directly comparable statistics are not available for the US, but in 2013, $73 \%$ of aggravated assaults involved weapons (FBI, 2014a) and $94 \%$ of homicides involved weapons (FBI, 2014b). Notably, two-thirds of US homicides involved a firearm.

In addition to measuring how much weapon carrying and weapon use takes place, we may wish to know why it occurs and in what circumstances. Again our sources of data on this are somewhat limited. Self-reports surveys can suffer from unreliable reporting, weak sampling and question design and their question design often overestimates the predictability of violent interactions. Crime reports can suffer from uneven reporting and inconsistencies in the way data are recorded. However, as in most offender decision-making, prospective, controlled methods for studying the role of weapons in violence would be unethical in the real world, and can lack ecological validity when explored in virtual or simulated environments. Qualitative studies - particularly if we are interested in learning about internal decision-making processes - can suffer from inaccurate responding as a result from social desirability, cognitive dissonance and imperfect memories.

Despite their limitations, surveys and crime reports are a valuable source of data for understanding the outcomes of crime involving weapons. Every year the details of thousands of criminal interactions are recorded and made available for analysis. However, these data only provide a 'black box' understanding of the outcomes of these incidents. Summaries of incidents tell us what went in and what came out, but these crude outcomes, such as offender attacked/did not attack or victim injury/no injury, do not provide sufficient detail to thoroughly understand the psychological mechanisms and intentions of the weapon user. A contrary argument could be that the crude quantification of violence into a set of binary outcomes is less prone to error or bias than the personal, retrospective accounts of offenders 
and victims. Both data sources have their strengths and weaknesses, which should be considered when drawing conclusions from the research literature.

While qualitative research - both interviews and ethnographies - can address some of the gaps inherent in large-scale databases, the vast majority of this research is based upon US samples and focuses almost exclusively on firearms. This is not particularly surprising given the high prevalence of firearm-related morbidity and mortality in the US, but many of the features of firearms, such as their ability to cause serious harm from a distance, their highly lethal nature and their varied legality, mean that the way in which they are used cannot be generalised to all weapons or populations outside the US.

\section{A RATIONAL INTERPRETATION OF WEAPON CARRYING AND USE}

The following section explores the behaviours of weapon carrying and weapon use from a rational perspective. Beginning with weapon carrying, the decision stages that lead to weapon use are presented and critically discussed.

\subsection{The decision-making stages of weapon use}

Decision-making about weapons is a multifaceted process. Assuming a logical pathway from weapon-carrying to weapon use, the individual faces a range of choices, which are summarised in figure one. Firstly, there is the initial decision on whether to carry a weapon and the weapon(s) of choice, which later will be been shown to be governed in part by community, availability and a wide range of economic, dispositional and social factors. The motivation to offend must then emerge. Some evidence suggests that the weapon itself can be instrumental in generating this motivation. When selecting a target, the presence of a weapon and the particular type of weapon carried can influence the pool of available victims and be a deciding factor in target selection of offence strategy. Upon making contact with the victim, the offender still faces the decision to make the victim aware of the presence of a weapon. The presentation of the weapon will prompt a quick escalating or de-escalating response from the victim, which in turn, will affect the offender's decision on how to use their weapon. At each stage of this complex decision-making process the weapon is not always a passive instrument, but can actually determine the offender and victim's next moves. In attempting to understand these various stages, it is important to recognise that 
decision-making in stressful situations is often not rational or measured, is often performed incompetently and does not necessarily follow a logical pathway (Collins, 2008; Van Gelder, 2013). Furthermore, it should be remembered that the decision-making pathway detailed in figure one is a simplified model of what in reality is a complex and non-linear process. Much weapon use is not planned and the eventual weapon user may not have carried a weapon to the interaction. Therefore, offenders can enter the decision-making tree of weapon use at almost any stage. Indeed, given the lethal potential of weapon use, a person who emerges as a perpetrator of violence may even have begun the interaction as a target for victimisation.

Figure 1. Decision stages of weapon use

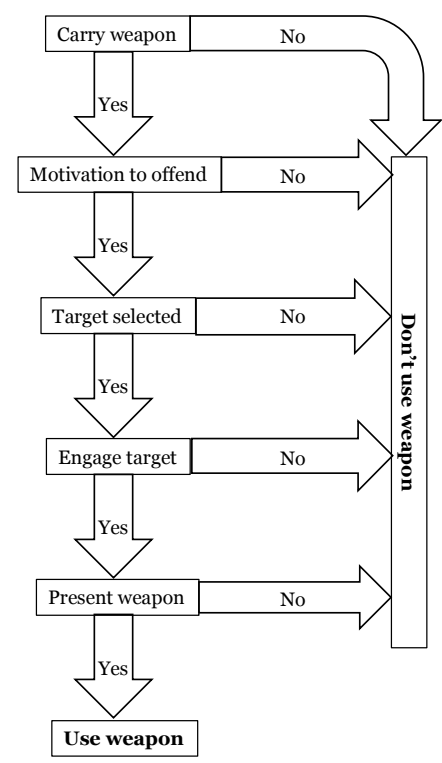

\subsection{The decision to use a weapon: Rationality and intentions}

While there has been considerable discussion since the 1950s regarding how and why offenders have selected particular weapons to facilitate their crimes, the literature that uses primary accounts of this decision is small. Furthermore, because of this lack of first-hand account research, much of the conclusions drawn by researchers about offender intentions have been speculative and based upon simple rational models despite the strong evidence that many offenders are prone to making decisions that appear irrational to the general public (D. Cornish \& R. Clarke, 1986). To date, no research has attempted to thoroughly interpret the decision to carry or use a weapon within a framework of 'bounded' rationality 
that could more accurately reflect the decision-making styles of many offenders. However, what research has looked at the factors influencing weapon carrying and use has shown these behaviours to be complex, often contradictory and guided by much more than a rational calculation of utility.

To understand offenders' decision-making, we need to gain an insight into their intentions prior to an offence. We can start from the position that weapon selection broadly reflects the offensive intentions of the offender. To a large extent the evidence supports this: during assaults, they greatly increase the severity of physical (Apel, Dugan, \& Powers, 2013; I.R. Brennan, Moore, \& Shepherd, 2006; Felson \& Messner, 1996; Saltzman, Mercy, O'Carroll, Rosenberg, \& Rhodes, 1992) and psychological harm (Brewin, Andrews, Rose, \& Kirk, 1999), while in robbery they often reduce the likelihood of injury to a victim and facilitate easy execution and escape (Feeney, 1986; Tillyer \& Tillyer, 2014). However, while weapons are capable of causing physical harm, they can also be a mechanism for protection. In fact, for most owners of legal firearms in the US, protection against crime is the most cited reason for owning a gun (Cook \& Ludwig, 1997). In reality, as most gun owners will never use their firearm in the prevention of crime, the value of firearms is largely emotional rather than practical. The reasoning of gun owners - that widespread gun ownership deters potential criminals and that owning a gun can protect a person from an assailant - is a rational one. However, the effectiveness of gun ownership and gun carrying in protecting the owner has become hotly contested in the US (Black \& Nagin, 1997; Hemenway, 1997; G. Kleck, 1999). Several of the articles cited in this chapter are disputed by different sides of the firearm debate in the US but this argument is not the focus of this chapter. Therefore, individuals studies described in this chapter, particularly regarding the role of firearms in victim outcomes, should be interpreted with caution and as part of a larger discussion around the use of weapons in crime.

\section{THE UTILITY OF WEAPONS}

In order to understand how offenders might weigh up the benefits and costs of weapon use, it is helpful to consider how weapons can be used in crime and to acknowledge the potential negative consequences of this behaviour. It is also important to recognise that victims are not helpless targets in these interactions and the calculations that an offender requires a victim to make are also discussed. 


\subsection{Benefits}

In robbery, potential victims appreciate the harm that weapons permit and so may be more likely to hand over property without resistance. The avoidance of physical and verbal resistance to robbery can make it a faster and less conspicuous event, which reduces the likelihood of capable guardians intervening or the offence being detected by formal or natural surveillance (Cook, 1991). For opportunistic robbers, carrying a weapon that can overpower even the strongest person greatly increases the pool of potential victims. Careful selection of weapons can also overcome guardians and target hardening measures in robbery. Finally, the ability to cause harm from distance can also allow an offender to control several victims simultaneously and to facilitate escape before victims seek help (Cook, 1991).

During assaults, weapon use may make it easier to control the forensic evidence than a bodily assault because less physical contact will reduce the transfer of trace evidence. Also, the ability to remove the weapon from the crime scene and dispose of it effectively will complicate the subsequent criminal investigation. Violence with a weapon reduces the need for physical strength or skill, limits the potential for counter-attack, facilitates surprise attacks and escape and may reduce the uncertainty of the violent incident by making it faster and more lethal. Weapons can also overcome target hardening measures to protect against violence. For example, the right weapon can overcome body armour, armed resistance and most physical barriers.

It should also be remembered that weapons do not have to be used to have value. Frequent weapon carrying by an offender can lead to a reputation for dangerousness or excessive or gratuitous violence. For some offenders, a reputation for disproportionality in violence or use of an incongruously lethal weapon such as a machete, can have long-term benefits such as protection from victim reporting, protection from counter-attack and reduced future resistance from other victims (Levi \& Maguire, 2002).

\subsection{Costs}

While weapons have a great many advantages over unarmed attacks, there are a number of potential costs that prohibit their use. In general, the benefits of weapon use are seen during the commission of an incident while the costs of weapon use are often incurred after the incident. The primary cost in an offender's decision to use a weapon is a legal one that affects both the likelihood of being apprehended and the severity of punishment. 
The use of a weapon in violence is one of the strongest predictors of a victims regarding the incident as a crime (I.R. Brennan, epub) and it almost doubles the likelihood that the incident will be reported to the police (I.R. Brennan, 2011b). Cook et al (2007) have shown that the use of a gun in gang violence often brings unwanted attention from the police to a gang's activities, increasing ancillary costs to a drug business. These factors combined inevitably increase the likelihood of detection by police and the perceived costs of weapon use.

In most legal systems, weapons are regarded as 'aggravating factors' in sentencing, resulting in more severe punishments (Cook, 1987a) and can carry mandatory sentences that unarmed violence does not. Therefore, all things being equal, the punishment costs of weapon use are higher than those of unarmed violence.

In addition to legal costs, certain weapons can also have time and resource costs. Cook et al (2007) provide a detailed discussion of the difficulties of sourcing reliable firearms in a 'thin' market in Chicago. Firearms and ammunition on the black market sell for substantially more than their worth on the open market, they can be unreliable, may have been previously used in another crime and require considerable time, effort and risk to acquire.

\subsection{Victim risk calculus}

The power of the weapon in victim management or coercion does not rest solely with the offender; the victim must also acknowledge the weapon and its potential for harm.

Therefore, the success of weapon use, at least in robbery, is dependent on both the offender and the victim making rational calculations. An intended victim who shows no fear when faced with a weapon briefly retains their power in the conflict; obviously, this is a high-risk strategy. The offender must correctly make a judgement that the lethality of the weapon and the perceived probability that they will use it outweighs the financial or egotistical cost of the robbery for the victim. The offender's script for the incident relies upon their victim being rational along with a shared valuation of the variables in the incident. For example, to protect a valuable item of property, a victim may be willing to take a chance against an offender with a knuckleduster, but not against an offender with a knife. Similarly, to protect their masculine identity, a male victim may be willing to take their chances against a female with a club, but not a female with a gun. Successful offenders must have accommodated 
these factors in their offence planning. The consequences of weapon use when risk has been miscalculated is a topic of great interest to violence researchers and, summarised later in this chapter, the effectiveness of victim resistance to weapon use is one of the most contested areas of this field (Cook, 1986).

\section{WHY OFFENDERS CHOOSE TO CARRY AND USE WEAPONS}

This section addresses some of the assumptions that have been made about weapon use in the public domain and in the research literature, specifically regarding the extent to which carrying and using particular weapons reflects the intentions of the user. Once these issues are addressed, the chapter critically interprets weapon carrying and use from a variety of theoretical perspectives.

\subsection{Weapons and intentions}

Retrospective, quantitative studies of offender decision-making are often bound by the assumptions that offenders had stable, initial intentions, which they followed through on; that they were in control of the situation; and that they did not make any errors in their execution of the crime. Unfortunately for these studies, interviews with small samples of weapon users have shown that the success of offenders in executing their intentions can be overestimated (Collins, 2008; Feeney, 1986), weapon availability, selection and use are not always optimal (Cook et al., 2007) and crimes with weapons do not always go as planned (Phillips \& Maume, 2007a). The following section discusses the evidence for and against the position that the outcomes of weapon use reflect the initial goals of the weapon user. This topic is explored through three main assumptions that underlie our ability to infer intentions from actions in weapon users: that the lethality of a weapon is constant; that an offender's weapon of choice is always available; and that offenders control the use of their weapons.

4.1.1 Lethality, incompetence and the uncertainty of criminal interactions

Wolfgang (1958) proposed that the type of weapon carried or used by an offender reflects their intentions prior to the incident, i.e. the more lethal the weapon, the more lethal the intent and the harder the target of robbery, the more lethal the weapon. While this perspective is rational, its universality is highly contested. Critics have argued that it underestimates the unpredictable nature of violent incidents and attributes too much control 
over the situation to the motivated offender (Phillips \& Maume, 2007b; R. T. Wright \& Decker, 1997; Zimring, 1968, 2004).

Firstly, the relationship between weapons and harm is non-linear. Newton and Zimring (1969), Apel et al. (2013) and the England and Wales Home Office (2012) have all found that weapon use tends to be associated with no injury or major injury; rarely do they cause minor injury. Secondly, illustrating that robberies - ideally quick, non-violent interactions - can often go awry, Cook (1987a) ranked the lethality of particular weapon types in robberies of unarmed targets, showing that despite their supposedly increased coercive power, gun robberies are three times as likely to result in target fatality than robberies with knives and twenty times more likely to result in fatality than unarmed robberies. Emphasising the importance of weapon lethality in violent outcomes, Cook (1991) noted that "many homicides are not the result of a sustained, deliberate intent to kill but rather are etiologically indistinguishable from a larger set of assaults and robberies in which the victim does not die" (p.4). When a criminal interaction has as much uncertainty as a robbery, the lethality of the weapon raises the stakes for offender and target considerably. Thirdly, a common assumption about weapons is that, when they are used in violence, they always inflict damage on the target. However, a range of sources suggest that this is not true. Kleck and McElrath (1991) cite National Crime Survey data that showed only $19 \%$ of gunshots actually hit their intended target and 55\% of knife attacks resulted in a knife wound. Collins (2008), using photographic and video evidence of conflict also suggests that the stress of violent situations makes many motivated fighters incapable of or at least incompetent at completing violence.

Therefore, it is highly likely that the lethality of a weapon used in violence influences the outcomes of that incident. However, to infer an offender's intentions from these few pieces of information underestimates the complexity and the unpredictability of the violent event.

\subsubsection{Decisions about weapons of choice}

While Wolfgang's proposal that the lethality of the weapon used by an offender provides a retrospective insight into their intent may be too rational, there is convincing evidence that offenders do make some calculated decisions about their choice of weapon. A survey of 1,874 male prisoners in the US and found that offenders could generally provide rational reasons 
for their selection of a particular weapon type including victim management and coercion, sentencing practices, legal constraints and availability (J. D. Wright \& Rossi, 1986). Wright and Decker's study of armed robbers also provided valuable insight into offenders' weaponrelated decision-making (R. T. Wright \& Decker, 1997). While they reported that the presentation of weapons was instrumental in victim management, weapons were also often used against their victims to aid their escape, to dominate their victims and to speed up the robbery. Feeney (1986) and Cook et al (2007) have shown that offenders frequently carry and use firearms that are incapable of firing. Rationales for this included a desire to avoid injuring anyone, to maximise the chances of success while avoiding a harsher sentence that could come with robbery with an active firearm and an awareness that much of the time simply showing a gun to a potential target is enough to deescalate a situation.

Often a weapon - specifically, the right type of weapon for the intended offence - is not always available. As Wright and Rossi (1986) have noted, offenders often have clear reasons for not using particular weapons in their offending. Offenders may realise the potential for excessive harm to victims that accompanies weapon use, the greater potential for their own harm if they lose control of the incident, a distaste for weapons (Harcourt, 2006), the 'challenge' of robbery or assault without a weapon or a discord between their desired image and the use of weapons or particular weapon types. In 'thin' markets where firearms are often expensive or difficult to source, potential offenders must compromise in the weapons they select (Cook et al., 2007). As yet it is unknown how much offenders are willing to compromise on their weapon of choice. Questions to answer include: can the choice of weapons available to an offender be so sub-optimal as to prevent the crime being committed and, when faced with a choice between more and less lethal alternatives, what is the more likely choice?

\subsection{3 'Weapon instrumentality'}

It has long been hypothesised that the presence of a weapon, through its cultural association with violence, can increase the potential for aggressive behaviour. This has come to be know as the 'weapons effect' or the 'weapon instrumentality' hypothesis. Berkowitz and LePage (1967) produced the first experimental evidence for this effect, but several attempts at replication were inconclusive (Carlson, Marcus-Newhall, \& Miller, 1990), leading to a belief that the effect observed by Berkowitz and LePage (1967) was an artefact of the experimental procedure. However, a meta-analysis of 'weapons effect' experiments (Carlson et al., 1990) 
found an overall effect of the presence of weapons on aggression. Later research found that weapons-associated words could also produce an enhanced aggressive response (Subra, Muller, Begue, Bushman, \& Delmas, 2010) and, particularly important in understanding the motivation to carry a weapon, that carrying a weapon increases the perception that other people are also carrying weapons (Witt \& Brockmole, 2012).

The implications of these findings for offender and victim decision-making are considerable. An extension of this finding is that the presentation of a weapon, for example in a robbery, could alter the aggressive intentions of the robber. Similarly, using a weapon to threaten someone could lead unexpectedly to violence (Feeney, 1986). The 'weapons effect' could also mean that the presentation of a weapon to a victim could increase the likelihood of their resisting aggressively. Whether this is true in reality is uncertain and is discussed in the later section on offender responses to victim resistance. While the 'weapons effect' may serve to prime the victim towards aggression, the stress of the situation and individual intent are likely to be a more influential factor in their decision-making (Phillips \& Maume, 2007b).

Wells and Horney (2002) noted a difficulty of separating the harming effect of weapons from that of individual intent. Two conflicting possibilities are apparent: if a weapon is associated with increased harm, this may simply reflect the intention of the offender to cause more harm, or there may be an instrumentality effect of the weapon that influences the offender to cause more serious harm than originally intended. Using a novel within-individual casecontrol method, Wells and Horney compared offenders' use of weapons to comparable incidents of potential conflict that did not involve weapons. Their study found that, controlling for intention, when an offender possessed a weapon they were more likely to attack an adversary. Interestingly, this finding contradicted that of Kleck and McElrath (1991), who had found, from victimisation data, that when an offender possessed a weapon they were less likely to attack the victim. The difference in these finding may be artefactual. Wells and Horney's study relied on offender account of weapon 'possession', whereas Kleck and McElrath's study relied upon victim accounts of weapon 'presentation'. These are not comparable stages of the weapon use pathway and the latter reflects a more advanced stage of the offence process.

\subsection{Theories of weapon carrying and weapon use}


Relatively few studies have identified weapon users as psychologically distinct from other violent offenders (I.R. Brennan, Shepherd , \& Moore, 2010), but identifying any differences between weapon using offenders and other violent offenders could provide valuable insight into the decision-making processes of weapon users. The research literature has not tended to view weapon violence as a distinct category of offending and so few comprehensive theories of weapon carrying or weapon use have been proposed. Three main approaches have been employed to understand weapon-related behaviour: rational choice, dispositional theories and differential association are presented below. As weapon carriers and weapon users are often treated separately, particularly in the epidemiological literature, theories for these two overlapping behaviours are presented separately. While the predominant focus is on weapon use, understanding weapon carrying can provide valuable insight into the precursory motivations of weapon users.

\subsubsection{Theories of weapon carrying}

Most theories of weapon carrying focus on three major motivations: self-protection/fear (Cook \& Ludwig, 1997; Harcourt, 2006), self-presentation (Harcourt, 2006; A. J. Lizotte, M. D. Krohn, J. C. Howell, K. Tobin, \& G. J. Howard, 2000; Sheley \& Wright, 1993) and utility (Feeney, 1986; Wolfgang, 1958). These motivations can exist simultaneously (Stretesky \& Pogrebin, 2007) and can often appear contradictory. Weapon-carriers who are motivated by the first two factors may never actually use their weapons in anger. However, those motivated by the third factor carry weapons to facilitate more criminal goals and, most likely, represent more dangerous individuals. The uncertain and dynamic nature of violent incidents, particularly when weapons are available, means that weapon carriers can quickly become weapon users, regardless of their initial motivations for carrying a weapon.

Studies that have explored weapon carrying have focused predominantly on adolescents and have sought to identify predictors of this behaviour rather than to establish a reliable prevalence rate. These studies found that many of the factors that predict weapon carrying are also the factors that predict violent behaviour more generally: male gender (Kodjo, Auinger, \& Ryan, 2003), late adolescence (Durant, Krowchuk, Kreiter, Sinal, \& Woods, 1999), social deprivation (A. J. Lizotte, M. D. Krohn, K. Howell, K. Tobin, \& G. J. Howard, 2000), substance misuse (DuRant, Getts, Cadenhead, \& Woods, 1995) and poor or deviant social support (Morrison, Furlong, \& Smith, 1994). Harcourt's (2006) detailed investigation into gun possession by juvenile offenders found a remarkably complex set of motivations for 
this behaviour that included emotional regulation, a sense of entitlement to gun possession, group identity and enacting masculine identities. Finally, important to bounded rational interpretations of weapon carrying is the evidence that the tendency to carry a weapon is influenced by the perception that one's peers also carry weapons (Bailey, Flewelling, \& Rosenbaum, 1997; Williams, Mulhall, Reis, \& DeVille, 2002) and that individuals who carry weapons overestimate the prevalence of their peers' weapon carrying (Bailey \& Hubbard, 1991). The belief that one's peer group regularly carry weapons inevitably has a normalising effect on attitudes towards weapons, which is likely to perpetuate the carrying of a weapons within that group (Strodtbeck \& Short, 1964).

Interestingly, few studies have attempted to identify differences between weapon carriers and weapon users. Among a school-based survey of Swiss adolescents, Thurnherr, Michaud, Berchtold et al (2009) found little difference between weapon carriers and weapon users. Compared to weapon carriers, male weapon users were more likely to be foreign born, to live in urban areas, to be undertaking an apprenticeship (as opposed to still being in school), to have poor school connectedness, to have engaged in unsafe sex and to quarrel while under the influence of substances. Besides the usual predictors of offending behaviour, there was little here to distinguish between the groups. There was no difference in history of victimisation, family factors or substance use involvement or diverse offending behaviour, which are common predictors of violent behaviour. The study found even fewer differences between female weapon carriers and users.

Dijkstra, Gest, Lindenberg et al (2012) tested three hypotheses for why adolescents carry weapons: to reflect their trait aggression, in response to perceived or actual threat of victimisation and in response to peer influence and peer behaviour. In general, aggression and weapon-carrying among peer networks predicted weapon carrying while victimisation did not. However, likelihood of weapon carrying did increase when aggression interacted with victimisation. One explanation of this interaction effect is that it reflects the offendervictim overlap and weapon-carrying is a normal part of a more aggressive lifestyle that involves victimisation and offending. This is an important finding: one of the most commonly cited reasons among offenders to carrying a weapon is 'self-defence' (J. D. Wright \& Rossi, 1986) but this fear of violence should be understood within the context of a risky lifestyle and living environment. 


\subsubsection{Theories of weapon use}

\subsubsection{Weapon use as rational}

The first theory of weapon use is that the use of a weapon is a rational decision, i.e. it maximises benefits while minimising costs to the user. Therefore, a weapon-using offender should be more likely to succeed with their intended crime and less likely to suffer the consequences of this crime in the form of detection, punishment, retaliation or harm to self.

To begin assessing the rationality of weapon use, we can look at the circumstances where weapon use is more likely that unarmed violence and assess this through a rational lens. Unfortunately, as it is gleaned from victimisation surveys and police records, much of the event-level information is somewhat crude and considerable details is lost with regards the psychological process of offending.

In terms of situational and contextual predictors of weapon use, Baumer, Horney, Felson and Lauritsen (2003) found that firearms were more likely to be used in assaults in disadvantaged neighbourhoods. They argue that, because weapon carrying is more prevalent in these areas, that more lethality in the form of weapons is used to required to succeed in committing crime. Controlling for neighbourhood disadvantage, Burgason, Thomas and Berthelot (2013) found that offender substance use, the incident taking place in a home and victim age were all negatively related to the likelihood that a gun was presented. Guns were more likely to be presented in incidents where the victim was male, black and from outside the community. This study is limited by its binary focus on firearms. However, research by Rennison, Jacques and Berg (2011) addressed this gap by including all weapons and placing them on a spectrum of lethality. Their study found that relational distance predicted weapon lethality. From these identifying factors it is possible to surmise that availability of firearms played an important role in determining weapon use but that victim characteristics and victim-offender relational distance affect weapon choice and use. One rational explanation of this is that male, stranger victims represent greater uncertainty about their potential for resistance and retaliation which necessitates the use of a weapon.

A predominant feature of many lethal weapons is that they neutralise differences in physical power between two people. Therefore, one possible reason for weapon carrying and weapon 
use is that those with less physical power will be more inclined to use weapons against stronger physical opponents. Stretesky and Pogrebin (2007) describe an interview with an offender who, because of a reputation as an effective hand-to-hand fighter, was repeatedly subjected to surprise attacks with weapons. Ironically, this offender felt forced to carry a gun because of this ability to fight without one. A study of victims of unarmed and weaponrelated violence by Felson and Messner (1996) found that weapon use mediated the effect of physical strength on injury to the victim and Kleck and McElrath (1991) found that female murderers - less strong on average than makes - were less likely to use guns against females than against males. Therefore, there is some evidence to support the 'equalising' hypothesis of weapon use. An unfortunate extension of this logic is that belligerents will continuously address this imbalance by using more and more lethal weapons (I.R. Brennan \& Moore, 2009; Decker \& Van Winkle, 1996; Horowitz, 1983).

As evidence that offenders choose to use weapons and select weapons to suit their offending purpose, Beauregard and Leclerc (2007) found that, among a sample of 69 serial sexual offenders, when weapons were used the primary reason for this was to overcome victim resistance. This study indicates that this type of offender also frames their decision to use a weapon as part of a rational plan and that sexual offenders only use weapons when they feel that they have to or when the weapon plays a specific gratification-related role within the offence. In terms of offence characteristics, weapon users were less likely to use confidence approaches or vehicles and were more likely to attack outdoors and using surprise attacks. The weapon likely played an important part in permitting such crude tactics. The potential power of the weapon can neutralise the need for much planning, reduce the uncertainty and difficulty of confidence approaches and increase the pool of potential victims. The similarities of sexual offences using weapons and non-sexual offences using weapons is striking. In both sets of case, weapons permit greater potential for opportunistic offending and reduce the uncertainty associated with these crimes.

As noted in the section above on the costs of weapon use, this behaviour is more likely to come to come to the attention of the police and likely to yield more severe punishment than unarmed violence. If offenders are rational decision-makers, a consequence of enhanced punishment should be that weapon use decreases. Some of the juvenile offenders interviewed by Harcourt (2006) reported that the aggravating effect of firearms on sentencing influenced their decision to avoid using guns. However, focusing on firearm use, the US National Research Council found limited support for an effect of enhanced sentencing 
for firearm-related crimes on firearm-related offences. When asked if they would use a gun to commit robbery again, $91 \%$ of convicted armed robbers surveyed in Western Australia stated that they would (Harding, 1990). More recent evidence suggests that focused deterrence may have a greater effect on firearm-related reoffending (Baraga \& Weisburd, 2015) but its US, firearm focus limits the generalisability of this phenomenon to this sample while there is a dearth of rigorous evaluations of these policies from elsewhere in the world.

In spite of the evidence that weapon use increases the likelihood of detection, Harding (1993) reported that a group of convicted armed robbers believed that the use of a weapon decreases the likelihood that they will be apprehended. It should be recalled that what appears rational to one person may not appear rational to the next (D. B. Cornish \& R. V. Clarke, 1986). A bounded rational interpretation of weapon use is that people who use weapons interpret and discount the risk of harm to victims in a different way to other individuals, which could be assessed through attitudes to risk, or that they care less about the potential harm to victims than others do. Furthermore, the aggravating component of weapon use on the severity of sentencing suggests that weapon-users may be more inclined to discount the potential risks of weapon use. Following this logic, Brennan, Moore and Shepherd (2010) found that, compared to violent offenders who hadn't used weapons, weapon users took more risks on a gambling task. To date, this is the only evidence to suggest that weapon users think differently to other violent offenders. The small sample employed by Brennan et al (2010) means that until further supporting evidence is presented, any assumptions that weapon users calculate risk differently to other offenders must be made cautiously.

4.2.2.3 Weapon use reflects a violent disposition

There is growing evidence that in terms of length and diversity of criminal career, weapon using violent offenders are simply more violent than other offenders and that weapon use facilitates their desire to harm others.

Rothman, Hemenway, Miller and Azrael (2005) found that domestic abuse offenders who had previously used a knife to threaten or harm a partner were 8.8 times more likely to later use a gun to threaten a partner again and Woodworth, Freimuth, Hutton et al (2013) have shown that sadistic paraphilia is strongly predictive of weapon use by sexual offenders. 
Michie and Cooke's (2006) found that the use of a weapon in violence was an indicator of a more seriously violent individual compared to offenders who committed violence without a weapon. Weapon use was also found to predict psychopathy (Cooke \& Michie, 2006) and trait anger (I.R. Brennan et al., 2006; Cooke \& Michie, 2006). Dawson, Goodwill and Dixon's (2014) study of UK serious sexual offences found nothing demographic to distinguish between weapon and non weapon using offenders. However, consistent with the findings of Michie and Cooke (2006) with non-sexual offenders, weapon users had more extensive offending histories.

Several studies have shown greatly increased prevalence of weapon carrying and weapon use among people with psychotic disorders (Lewis, Baranoski, Buchanan, \& Benedek, 1998; Lewis \& Bunce, 2003; Stueve \& Link, 1997; Swanson, Hozer, Ganju, \& Jono, 1990). While not condonable, weapon carrying and use among those experiencing psychotic episodes is understandable. The altered perception of reality, combined with extreme fear and confusion that these symptoms can produce could easily make weapon use a reasonable action. As Lewis et al (1998) noted tragically, "the use of weapons by psychotic mothers was rarely related to punishment or frustration. Most frequently, it related to delusions involving the child being in danger or the child itself being dangerous" (p.617).

Langevin and Curnoe's (2013) study of 1,533 sexual offenders in Canada who received psychiatric assessments found that weapon use was a statistically significant predictor of sadism, psychosis, suicide attempts, personality disorder, psychopathy and Attention Deficit Hyperactivity Disorder. Furthermore, weapon use was also associated with alcohol problems and drug problems and weapon users were more likely to be under the influence of some substance at the time of the offence. Weapon use was associated with lower intelligence and less advanced education. In terms of offending history, weapon use was associated with earlier age of first offence, longer criminal career, more violent offence convictions, more total convictions and more court appearances. Again, many of these clinical, historical and criminogenic characteristics are indicative of more diverse and serious offending potential, which Michie and Cooke (2006) have demonstrated among non-sexual weapon using offenders. This evidence lends support to Michie and Cooke's proposal that weapon use is a valuable indicator of more serious violence potential, suggesting that the reasons for weapon use are not fear-related but instrumental in committing increasingly violent crime. 
4.2.2.3 Weapon use as a consequence of differential association

Weapon use may reflect the level of availability and exposure to weapons in an individual's life or community. In a study of the increase in homicide in the US in the late 1980's and early 1990's, Blumstein and Cork (1996) pointed to the increase of firearm use as a major cause. They surmise that the increasing prevalence and severity of violence caused by drug markets created a need for more accessible and more lethal weapons. From individuals involved in drug markets, access to firearms spread through peer networks to those not involved in drug markets. This, in turn, escalated the level of lethal violence outside drug markets, which perpetuated the need for access to firearms for self-defence.

Cook (1979) showed that the per capita availability of legal guns predicted rates of firearm use in robberies and Cook and Ludwig (2004) found that teen gun carrying was related to the prevalence of gun ownership in their community. However, there was no relationship between carrying other types of weapon and community gun ownership. Harding (1990, 1993) has suggested that it is not the prevalence or availability of weapons but the context in which a community uses weapons that influences the likelihood that they will be used in interpersonal violence. Harding (1993) found that the relationship between gun use and gun availability was mediated by the role of firearms as 'utilitarian', i.e. for farming or practical purposes. In addition, the status of the individual who introduced the offender to guns was negatively related to the offender using a gun: armed robbers who were introduced to firearms by a father or uncle were less likely to use a gun than those introduced to guns by siblings, cousins or peers. This suggests that the decision to carry a weapon is motivated by perceived need, but weapon of choice is dictated by culture and availability.

\section{HOW WEAPON USE AFFECTS THE SUCCESS OF A CRIME}

\subsection{Responding to resistance - offender decision-making during robbery}

Particularly in robbery and sexual offending, overcoming victim resistance is the main purpose of weapon use. Therefore, from a decision-making perspective, it is valuable to understand how well weapons actually serve this function. We have already seen from Cook's work (Cook, 1976, 1987b) that even in robbery the lethality of a weapon predicts likelihood of victim fatality, but this work does not provide sufficient information about whether victims 
resisted the armed assailant. More recent, event-level studies have begun to collect this information.

Cook (1987a) studied US National Crime Survey data (1973-79) to determine the best course of action for victims to avoid injury when faced with a robber brandishing a weapon. This data set allowed a sequence of events from weapon presentation to weapon use to be constructed. When an offender experienced forceful resistance from the victim, $67 \%$ attacked compared to $29 \%$ when the victim offered no resistance and $30 \%$ when non-forceful resistance was experienced. From this it can be inferred that many offenders are willing to use weapons to do violence to as well as to coerce their victims. What is perhaps more surprising is that one in three offenders who faced forceful resistance form a victim chose not to use their weapon. As Cook noted, the crude event-level information in victimisation surveys prohibited any further interpretation of the offender's motivations and decisionmaking when facing forceful resistance. Perhaps victims were themselves carrying a weapon, perhaps the offender decided that the prize was no longer worth the risk or perhaps the offender had never intended to use the weapon and, realising that their bluff had been called, abandoned the robbery.

Baumer et al (2003) found that, during robberies, victims were less likely to resist when the offender had a gun and their likelihood of resisting was not affected by the presentation of any other weapon type. In assaults, Baumer et al (2003) found that victims were less likely to resist physically when an offender had a gun. However, victims were more likely to resist both forcefully and nonforcefully when the offender had another weapon. Tillyer and Tillyer (2014) also found that victims were less likely to be injured if the offender presented a weapon during a robbery, suggesting that victims were more compliant when faced with a weapon. Tark and Kleck's (2004) study of victim resistance to offenders across a variety of crimes, found no clear pattern in the effect of resistance with a weapon on victim injury.

Using data from the US National Crime Survey (1979-1985) and the FBI's Uniform Crime Reports (1982), Kleck and McElrath (1991) studied the role of weapons in the outcomes of violent incidents. They proposed that the possession of a weapon can play four roles in violent incidents: facilitation of an attack, for example of a stronger person by a weaker person; triggering of an attack by priming the weapon carrier towards violence - the 'weapon effect'; inhibition of an attack through "excessive lethality" (ibid., p.673); and 
redundancy wherein presentation of a weapon, with its ability to shift the balance of power to the possessor, negates the need to use it. They found that, in general, incidents of threat between strangers were less likely to escalate to attacks when guns or knives were presented, but more likely to escalate when other weapons such as blunt objects and bottles were involved. It is notable here that the weapons that are more likely to result in attacks are also more likely to be 'opportunistic weapons' found at the scene of the incident. Whether the offender brought the weapon to the scene was not determinable through the data, so it is possible that the presentation of an 'opportunistic weapon' reflect some other feature of the incident, such as an offender's lack of control over the situation, which could also influence their decision to attack. Kleck and McElrath (1991) also attempted to determine the likelihood of victim injury following attack. Their analyses found that firearms were less likely to result in victim injury than other weapons, but that when victims were shot, they were more likely to die than if injured with another weapon type. In effect, these findings confirm the lethality of firearms, but show an approximately non-linear relationship between lethality and the hierarchy of victim injury (threat, attack, injury, fatality).

In general, the more lethal the weapon, the less likely the victim is to react aggressively to the offender, but it is unclear how victim resistance affects the likelihood that an offender wielding a weapon will use their weapon. It is certain, however, that when the offender does use the weapon, the relationship between weapon lethality and victim injury is a linear one. Therefore, in terms of offending success, weapon use is a high-reward-high cost activity: while the use of a weapon makes offending success more likely, the consequences when things do not go to plan - for offender and victim - are greatly increased.

\section{CONCLUSIONS}

Weapons are not a passive feature of crime. Just as sexual arousal is a driving factor in sexual assaults, the presence of a weapon in a potentially criminal incident is a driving factor in the outcome of that incident. In violence, the use of a weapon greatly increases the likelihood of severe injury for the victim. In robbery, the use of weapons and likelihood of injury is more complex, with weapons reducing the need for violence, but greatly increasing the severity of that violence when it happens. 
Decisions to carry and use weapons are complex and multifaceted. There is some evidence that illegal weapon carrying is more a consequence of a risky lifestyle than solely a response to perceived risk. Weapon of choice appears to be highly-influenced by cultural and community factors such as the prevalence of that weapon in the community and its use in neighbourhood violence, but there is clear evidence among convicted offenders of some measured calculation based on the lethality of the weapon, its intended use and the prospect of punitive consequences. There is also some evidence that weapons use in violence can serve as a marker for being a high-risk offender.

The evidence from event-level studies of weapon use in robbery suggests that victims are, in general, less likely to resist physically and less likely to be physically injured if an offender presents a weapon. While weapon use increases the likelihood of a crime coming to the attention of police and generally comes with harsher penalties than unarmed crime, enhanced punishment does not appear to affect weapon-related offending, although the evidence is sparse.

While weapon use can enhance the likelihood of successful offending, this success is dependent on the offender and victim having a common computation of the lethality of the weapon and the probability that it will be used. When these calculations are mismatched, the potential for serious injury is high. There is conflicting evidence that victim resistance precipitates weapon use against them, but clear evidence that, when used, weapons increases the likelihood of serious injury.

While research has sought to plot the pathways to sexual offending (Hudson, Ward, \& McCormack, 1999), homicide (Cassar, Ward, \& Thakker, 2003) and drunk driving (Wilson, Ward, \& Bakker, 1998), this approach has not been followed with regard to weapon use. Understanding the role of the weapon from the perspective of the user is essential if we are to reduce the perceived value of weapons and to emphasise the costs and unpredictability that comes with weapon carrying. As currently constructed, crime reports and victimisation surveys cannot provide the insight into the decision-making process that this complex behaviour requires. While qualitative studies by Cook et al (2007) and Harcourt (2006) have provided valuable insight into the economics of access to guns and the motivations for guncarrying, respectively, there is a great need for further qualitative work in this area to inform the development of theories of weapon use and to guide the larger-scale quantitative 
evaluations of weapons violence. In particular, given the dominance of firearms in the weapons-related literature, there is a need for this work to be undertaken outside the United States.

Finally, offender decisions and interactions with potential targets are situational phenomena, but they do not exist with a vacuum. In every weapon-related interaction between people, multi-level effects are in operation. Gang members must consider the effects of their actions for reprisals against their peers; police must think how their use of deadly force might reflect on the institution of the police; offenders may decide on weapon type within the bounds of what is culturally acceptable and must consider the impact of law and sentencing guidelines on their behaviour and personal liberty. Most research on weapon use attempts to understand this behaviour at only one or two levels of the social-ecological model, generally using a routine activities theory model with a rational choice framework. However, despite the methodological problems that it would impose, a full understanding of weapon use will only be gained by acknowledging the multi-levelled nature of decisionmaking. 


\section{References}

Apel, R., Dugan, L., \& Powers, R. (2013). Gender and injury risk in incidents of assaultive violence. Justice Quarterly, 30, 561-593.

Bailey, S. L., Flewelling, R. L., \& Rosenbaum, D. (1997). Characteristics of students who bring weapons to school. Journal of Adolescent Health, 20, 261-270.

Bailey, S. L., \& Hubbard, R. L. (1991). Developmental changes in peer factors and the influence on marijuana initiation among secondary school students. Journal of Youth \& Adolescence, $20,339-360$.

Baraga, A. A., \& Weisburd, D. (2015). Focused deterrence and the prevention of violent gun injuries: Practice, theoretical evidence and scientific evidence. Annual Review of Public Health, 36, 55-68.

Baumer, E., Horney, J., Felson, R., \& Lauritsen, J. L. (2003). Neighborhood disadvantage and the nature of violence. Criminology, 41(1), 39-71.

Beauregard, E., \& Leclerc, B. (2007). An application of the rational choice approach to the offending process of sex offenders: A closer look at the decision-making. Sexual Abuse: Journal of Research and Treatment, 19(2), 115-133.

Berkowitz, L., \& LePage, A. (1967). Weapons as aggression-eliciting stimuli. Journal of Personality and Social Psychology, 7, 202-207.

Black, D. A., \& Nagin, D. S. (1997). Do right-to-carry laws deter violent crime? Journal of Legal Studies, 27, 209-219.

Blumstein, A., \& Cork, D. (1996). Linking gun availability to youth gun violence. Law and contemporary problems, 59(1), 5-24.

Brennan, I. R. (2011a). In vino silentium? Individual situational and alcohol related factors in reporting violence to the police. Violence and Victims.

Brennan, I. R. (2011b). In vino silentium? Individual, situational, and alcohol-related factors in reporting violence to the police. Violence \& Victims, 26, 191-207.

Brennan, I. R. (epub). Victim reponses to violence: The effect of alcohol context on crime labeling. Journal of Interpersonal Violence, 1-25. doi: 10.1177/0886260514564068

Brennan, I. R., \& Moore, S. C. (2009). Weapons and violence: a review of theory and research. Aggression \& Violent Behavior, 14, 215-225.

Brennan, I. R., Moore, S. C., \& Shepherd, J. P. (2006). Non-firearm weapon use and injury severity: priorities for prevention. Injury Prevention, 12(6), 395-399.

Brennan, I. R., Moore, S. C., \& Shepherd, J. P. (2010). Aggression and attitudes to time and risk in weapon-using violent offenders. Psychiatry Research, 178(3), 536-539.

Brewin, C. R., Andrews, B., Rose, S., \& Kirk, M. (1999). Acute stress disorder and posttraumatic stress disorder in victims of violent crime. American Journal of Psychiatry, 156(3), 360-366.

Burgason, K., Thomas, S., \& Burgason, E. R. (2013). Community disadvantage, incident characteristics and the nature of violence: A multi-level analysis of gun use and extent of victim injury. Journal of Interpersonal Violence, 29, 371-393.

Carlson, M., Marcus-Newhall, A., \& Miller, N. (1990). Effects of situational aggression cues:a quantitative review. Journal of Personality and Social Psychology, 58, 622-633.

Cassar, E., Ward, T., \& Thakker, J. (2003). A descriptive model of the homicide process. Behavior Change, 20, 76-93.

Collins, R. (2008). Violence: a micro-sociological theory. Oxford: Princeton University Press.

Cook, P. J. (1976). A strategic choice analysis of robbery. In W. Skogan (Ed.), Sample Surveys of the Victims of Crimes. Cambridge, Mass: Ballinger.

Cook, P. J. (1979). The effect of gun availability on robbery and robbery murder: A crosssection study of fifty states. In R. H. Haveman \& B. B. Zeller (Eds.), Policy studies review annual (Vol. 3). London: Sage.

Cook, P. J. (1986). The relationship between victim resistance and injury in noncommerical robbery. Journal of Legal Studies, 15, 405-416.

Cook, P. J. (1987a). Robbery violence. Journal of criminal law and criminology, 78, 357376. 
Cook, P. J. (1987b). Robbery violence. The Journal of Criminal Law and Criminology, 78(2), 357-376.

Cook, P. J. (1991). The technology of personal violence Crime and Justice: a review of research (Vol. 14, pp. 1-71). Chicago: University of Chicago Press.

Cook, P. J., \& Ludwig, J. (1997). Guns in America: national survey on private ownership and use of firearms. Washington, D.C.: US Department of Justice.

Cook, P. J., \& Ludwig, J. (2004). Does gun prevalence affect teen gun carrying after all? Criminology, 42(1), 27-54.

Cook, P. J., Ludwig, J., Venkatesh, S., \& Braga, A. A. (2007). Underground drug markets. The Economic Journal, 117, F558-F588.

Cooke, D. J., \& Michie, C. (2006). The structure of violent behavior: A hierarchical model. Criminal Justice \& Behavior, 33, 706-737.

Cornish, D., \& Clarke, R. (1986). The Reasoning Criminal: Rational Choice Perspectives of Offending. New York: Springer-Verlag.

Cornish, D. B., \& Clarke, R. V. (Eds.). (1986). The reasoning criminal. New York: SpringerVerlag.

Dawson, P., \& Goodwill, A. (2013). A review of weapon choice in violent and sexual crime. Beijing Law Review, 4, 20-27.

Dawson, P., Goodwill, A., \& Dixon, L. (2014). Preliminary insights and analysis into weapon enabled sexual offenders. Journal of Aggression, Conflict and Peace Research, 6, 174-184.

Decker, S. H., \& Van Winkle, B. (1996). Life in the Gang: Family, Friends and Violence. New York: Cambridge University Press.

Dijkstra, J. K., Gest, S. D., Lindenberg, S., Veenstra, R., \& Cillessen, A. H. N. (2012). Testing three explanations of the emergence of weapon carrying in peer context: The roles of aggression, victimization, and the social network. Journal of Adolescent Health, $50(4), 371-376$.

DuRant, R. H., Getts, A. G., Cadenhead, C., \& Woods, E. R. (1995). The association between weapon carrying and the use of violence among adolescents living in and around public housing. Journal of Adolescent Health, 17, 376-380.

Durant, R. H., Krowchuk, D. P., Kreiter, S., Sinal, S. H., \& Woods, C. R. (1999). Weapon carrying on school property among middle school students. Archives Of Pediatrics \& Adolescent Medicine, 153, 21-26.

FBI. (2014a). Crime in the United States, 2013 - Aggravated assault table. from https://www.fbi.gov/about-us/cjis/ucr/crime-in-the-u.s/2013/crime-in-the-u.s.2013/violent-crime/aggravated-assault-topicpage/aggravated assault table aggravated assault types of weapons used perc ent distribution by region 2013.xls

FBI. (2014b). Crime in the United States, 2013 - Expanded homicide data. from https://www.fbi.gov/about-us/cjis/ucr/crime-in-the-u.s/2013/crime-in-the-u.s.2013/offenses-known-to-law-enforcement/expanded-

homicide/expanded homicide data table 7 murder types of weapons used pe rcent distribution by region 2013.xls

Feeney, F. (1986). Robbers as decision-makers. In D. B. Cornish \& R. V. Clarke (Eds.), The Reasoning Criminal: Rational Choice Perspectives on Offending. New York: Springer-Verlag.

Felson, R. B., \& Messner, S. F. (1996). To kill or not to kill? Lethal outcomes in injurious attacks. Criminology, 34, 519-545.

Harcourt, B. E. (2006). Language of the gun. London: University of Chicago.

Harding, R. W. (1990). Rational-choice gun use in armed robbery: The likely deterrent effect on gun use of mandatory additional imprisonment. Criminal Law Forum, 1(3), 427450.

Harding, R. W. (1993). Gun use in crime, rational choice and social learning theory. In R. V. Clarke \& M. Felson (Eds.), Routine activity and rational choice (pp. 85-102). London: Transaction Publishers. 
Hemenway, D. (1997). Survey research and self-defense gun use: an explanation of extreme overestimates. Journal of criminal law and criminology, 87, 1430-1445.

Home Office. (2012). Crime statistics: Nature of crime tables, 2011/12 - Violent crime. Retrieved 25 August 2014, from Home Office http://www.ons.gov.uk/ons/rel/crimestats/crime-statistics/nature-of-crime-tables--2011-12/rft-7-violence.xls

Home Office. (2014). Focus on violent crime and sexual offences, 2012/13 bulletin tables. Retrieved from: $\leq$ http://www.ons.gov.uk/ons/rel/crime-stats/crime-statistics/focuson-violent-crime-and-sexual-offences--2012-13/rft-table-1.xls $>$

Horowitz, R. (1983). Honor and the American Dream: Culture and Identity in a Chicano Community. New Brunswick: Rutgers University Press.

Hudson, S. M., Ward, T., \& McCormack, J. C. (1999). Offense pathways in sexual offenders. Journal of Interpersonal Violence, 14, 779-798.

Kleck, G. (1999). Degrading scientific standards to get the defensive gun use estimate down. Journal on Firearms and Public Policy, 11, 77-138.

Kleck, G., \& McElrath, K. (1991). The effects of weaponry on human violence. Social Forces, 69(3), 669-692.

Kodjo, C. M., Auinger, P., \& Ryan, S. A. (2003). Demographic, intrinsic, and extrinsic factors associated with weapon carrying at school. Archives Of Pediatrics \& Adolescent Medicine, 157, 96-103.

Langevin, R., \& Curnoe, S. (2013). Psychological profile of sex offenders using weapons in their crimes. Journal of Sexual Aggression.

Levi, M., \& Maguire, M. (2002). Violent crime. In M. Maguire, R. Morgan, \& R. Reiner (Eds.), The Oxford Handbook of Criminology (Vol. 3, pp. 795-843). Oxford: Oxford University Press.

Lewis, C. F., Baranoski, M. V., Buchanan, J. A., \& Benedek, E. P. (1998). Factors associated with weapon use in maternal filicide. Journal of Forensic Sciences, 43(3), 613-618.

Lewis, C. F., \& Bunce, S. C. (2003). Filicidal mothers and the impact of psychosis on maternal filicide. Journal of the American Academy of Psychiatry and the Law, 31(4), 459-470.

Lizotte, A. J., Krohn, M. D., Howell, J. C., Tobin, K., \& Howard, G. J. (2000). Factors influencing gun carrying among young urban males over the adolescent-young adult life course. Criminology, 38(3), 811-834.

Lizotte, A. J., Krohn, M. D., Howell, K., Tobin, K., \& Howard, G. J. (2000). Factors influencing gun carrying among young urban males over the adolescent-young adult life course. Criminology, 38, 811-834.

Michie, C., \& Cooke, D. J. (2006). The structure of violent behavior: A hierarchical model. Criminal Justice and Behavior, 33(6), 706-737.

Morrison, G. M., Furlong, M. J., \& Smith, G. (1994). Factors associated with the experience of school violence among general education, leadership class, opportunity class and special day class pupils. Education and Treatment of Children, 17, 356-369.

Newton, G. D., \& Zimring, F. (1969). Firearms and violence in American life. A staff report to the National Commission on the causes and prevention of violence. Washington, D.C.: U.S. Government Printing Office.

Office for National Statistics. (2013). Focus on: violent crime and seuxal offences, 2011/12. London: Office for National Statistics.

Office for National Statistics. (2014). Focus on violent crime and sexual offences, 2012/13. from www.ons.gov.uk/ons/rel/crime-stats/crime-statistics/focus-on-violent-crimeand-sexual-offences--2012-13/rft-table-1.xls

Phillips, S., \& Maume, M. O. (2007a). Have gun wil shoot? Weapon instrumentality, intent, and the violent escalation of conflict. Homicide Studies, 11, 272-294.

Phillips, S., \& Maume, M. O. (2007b). Have gun will shoot? Weapon instrumentality, intent, and the violent escalation of conflict. Homicide Studies, 11, 272-294.

Rennison, C. M., Jacques, S., \& Berg, M. T. (2011). Weapon Lethality and Social Distance: A National Test of a Social Structural Theory. Justice Quarterly, 28, 576-605. 
Rothman, E. F., Hemenway, D., Miller, A. D., \& Azrael, D. (2005). Batterers' use of guns to threaten intimate partners. Journal of the American Medical Women's Association, $60,62-68$.

Saltzman, L. E., Mercy, J. A., O'Carroll, P. W., Rosenberg, M. L., \& Rhodes, P. H. (1992). Weapon involvement and injury outcomes in family and intimate assaults. Journal of the American Medical Association, $267(22), 3043-3047$.

Sheley, J. F., \& Wright, J. D. (1993). Motivations for gun possession and carrying among serious juvenile-offenders. Behavioral Sciences and the Law, 11, 375-388.

Stretesky, P. B., \& Pogrebin, M. (2007). Gang related gun violence: socialization, identity, and self. Journal of Contemporary Ethnography, 36, 85-114.

Strodtbeck, F. L., \& Short, J. F. (1964). An explanation of gang action. Social Problems, 12, 127-140.

Stueve, A., \& Link, B. G. (1997). Violence and psychiatric disorders: Results from an epidemiological study of young adults in Israel. Psychiatric Quarterly, 68(4), 327342.

Subra, B., Muller, D., Begue, L., Bushman, B., \& Delmas, F. (2010). Automatic effects of alcohol and aggressive cues on aggressive thoughts and behaviors. Personality and Social Psychology Bulletin, 36, 1052-1057.

Swanson, J. M., Hozer, C. D., Ganju, V. K., \& Jono, R. T. (1990). Violence and psychiatric disorder in the community: Evidence from the Epidemiological Catchment Area surveys. Hospital and Community Psychiatry, 41, 761-770.

Sweeten, G. (2012). Scaling criminal offending. Journal of Quantitative Criminology, 28, 533-557.

Tark, J., \& Kleck, G. (2004). Resisting crime: The effects of victim action on the outcomes of crimes. Criminology, 42(4), 861-909.

Thurnherr, J., Michaud, P. A., Berchtold, A., Akré, C., \& Suris, J. C. (2009). Youths carrying a weapon or using a weapon in a fight: What makes the difference? Health Education Research, 24(2), 270-279.

Tillyer, M. S., \& Tillyer, R. (2014). Violence in context: a multilvel analysis of victim injury in robbery incidents. Justice Quarterly, 31, 767-791.

Van Gelder, J.-L. (2013). Beyond Rational Choice: the Hot/Cool Perspective of Criminal Decision Making. Psychology, Crime and Law, 19(9).

Wells, W., \& Horney, J. (2002). Weapon effects and individual intent to do harm: influences on the escalation of violence. Criminology, 4O(2), 265-296.

Williams, S. S., Mulhall, P. F., Reis, J. S., \& DeVille, J. O. (2002). Adolescents carrying handguns and taking them to school: psychosocial correlates among public school students in Illinois. Journal of Adolescence, 25, 551-567.

Wilson, L. A., Ward, T., \& Bakker, L. (1998). A descriptive model of the relapse process in disqualified drivers. Behavior Change, 16, 111-126.

Witt, J. K., \& Brockmole, J. R. (2012). Action alters object identification: wielding a gun increases the bias to see guns. Journal of Experimental Psychology: Human Perception and Performance, 38, 1159-1167.

Wolfgang, M. E. (1958). Patterns in Criminal Homicide. Philadelphia: University of Pennsylvania Press.

Woodworth, M., Freimuth, T., Hutton, E. L., Carpenter, T., Agar, A. D., \& Logan, M. (2013). High-risk sexual offenders: an examination of sexual fantasy, sexual paraphilia, psychopathy, and offence characteristics. International Journal Of Law And Psychiatry, 36(2), 144-156. doi: 10.1016/j.ijlp.2013.01.007

Wright, J. D., \& Rossi, P. H. (1986). Armed and Considered Dangerous: A survey of felons and their firearms. New York: de Gruyter.

Wright, R. T., \& Decker, S. H. (1997). Armed robbers in action: stickups and street culture. Boston: Northeastern University Press.

Zimring, F. E. (1968). Is gun control likely to reduce violent killings? University of Chicago Law Reivew, 35, 721-737. 
Zimring, F. E. (2004). Firearms, violence, and the potential impact of firearms control. Journal of Law, Medicine and Ethics, 32, 34-37. 